\title{
A mutation in KIR3DS1 that results in truncation and lack of cell surface expression
}

\author{
Maureen P. Martin • Véronique Pascal • \\ Meredith Yeager • John Phair • Gregory D. Kirk • \\ Keith Hoots • Stephen J. O'Brien • \\ Stephen K. Anderson • Mary Carrington
}

Published online: 14 September 2007

(C) Springer-Verlag 2007

In the original version of this manuscript, the address given for one of the authors - Keith Hoots was incorrect. The correct address is: Gulf States Hemophilia Center, University of Texas Health Science Center, Houston, Texas 77030, USA

The online version of the original article can be found at http://dx.doi. org/10.1007/s00251-007-0240-8

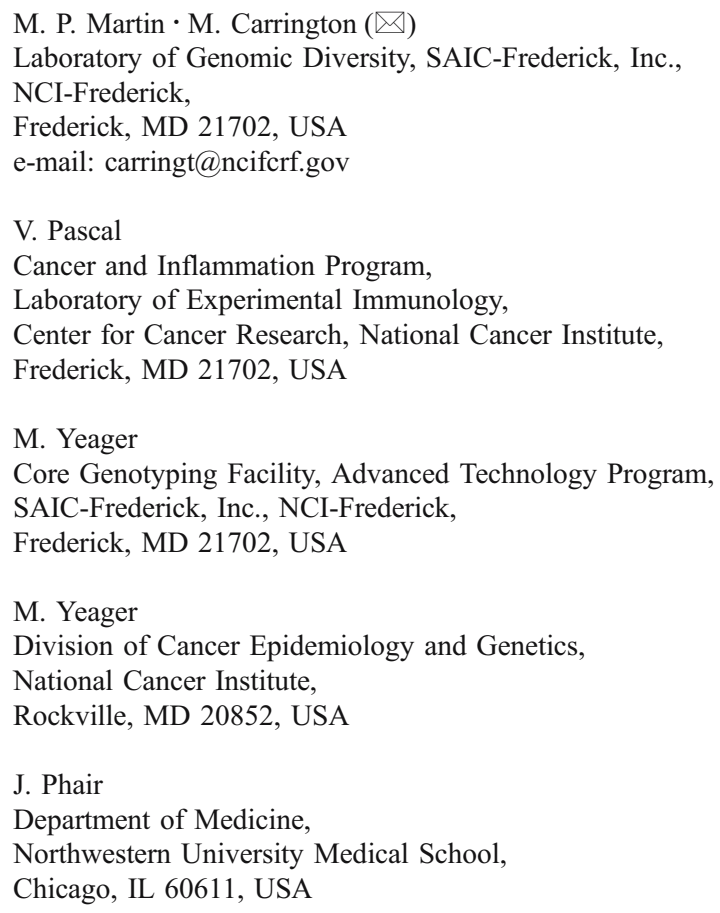

\section{G. D. Kirk}

Department of Epidemiology, Johns Hopkins University

Bloomberg School of Public Health,

Baltimore, MD 21205, USA

\section{K. Hoots}

Gulf States Hemophilia Center,

University of Texas Health Science Center,

Houston, TX 77030, USA

S. J. O'Brien

Laboratory of Genomic Diversity, National Cancer Institute,

Frederick, MD 21702, USA

\section{S. K. Anderson}

Cancer and Inflammation Program,

Laboratory of Experimental Immunology,

Center for Cancer Research, SAIC-Frederick, Inc., NCI-Frederick,

Frederick, MD 21702, USA 